\title{
Designation of two new pontoniine shrimp genera (Decapoda: Palaemonidae)
}

\author{
A. J. BRUCE \\ Division of Natural Sciences, Northern Territory Museum, \\ PO Box 4646, Darwin, Australia 0801
}

(Accepted 4 August 1992)

\begin{abstract}
Two new pontoniine genera are designated, Pseudopontonia gen. nov., for Pontonia minuta Baker, and Anchiopontonia gen. nov., for Pontonia hurri Holthuis, both genera being presently monospecific. Pontonia minuta is known only from south and eastern Australia, and is of unknown commensal association. Anchiopontonia hurii, an associate of spondylid bivalves, known from the Marshall and Tuamotu Islands, is also newly recorded from the Ryukyu Islands.
\end{abstract}

KeYwords: Crustacea; Palaemonidae; Pontoniinae; new genera; Pseudopontonia; Anchiopontonia; Indo-West Pacific

\section{Introduction}

In a recent publication (Bruce, 1991), it was noted that the genus Pontonia Latreille exhibited an unusually wide range of morphological variation that suggested a probable polyphyletic origin, possibly in coevolution with different types of host aninials. At present some nine species are referred to the genus in the Indo-West Pacific region, with a further 14 in the Atlantic-Mediterranean and East Pacific regions, not including the rather dubious $P$. unidens Baker. Two species contrast strongly with the majority of these species and exhibit morphological differences that justify the designation of new monospecific genera, thereby reducing the heterogeneity of the species presently included in Pontonia s. str.

\section{Pseudopontonia gen. nov.}

Definition. Small shrimps of robust, subcylindrical body form. Rostrum well developed, thickened, broad, blunt distally, without dorsal carina, unarmed. Carapace smooth, glabrous, inferior orbital angle bluntly produced, orbit feebly developed; supraorbital, epigastric, hepatic and antennal spines absent, anterolateral margin of branchiostegite produced. Abdomen smooth, glabrous, pleura rounded. Telson normal, with two pairs of large dorsal spines, posterior margin with six pairs of small spines. Antennule with short stylocerite, flagella short, upper flagellum short, feebly biramous. Antenna with basicerite stout, unarmed, scaphocerite normal, distolateral tooth large. Eye normal, cornea globular. Mandible normal, without palp, incisor process multidentate; maxillula with feebly bilobed palp, upper lacinia broad; maxilla with short, simple palp, basial endite reduced, simple, coxal endite absent, scaphognathite normal, anteromedial margin emarginate; first maxilliped with reduced simple palp, basial and coxal endites fused, broad, exopod with flagellum reduced, 
caridean lobe narrow, epipod triangular; second maxilliped with normal endopod, dactylar segment narrow, medially spinulate, coxa medially produced, exopod short, broad, lanceolate, with lateral sparsely plumose setae, distal setae lacking, epipod small, simple, without podobranch; third maxilliped short, robust, ischiomerus and basis completely fused, exopod reduced, sparsely setose, coxa medially inclined, with low rounded lateral plate. Fourth thoracic sternite without median process. First pereiopods slender, fingers feebly subspatulate, simple. Second pereiopods short, chelae small, stout, similar, subequal, fingers without molar processes. Ambulatory pereiopods robust, dactyls strongly biunguiculate. Uropod with protopodite unarmed, exopod with lateral margin unarmed. Ova large, larval development abbreviated.

Type species. Pontonia minuta Baker, 1907.

Systeriatic position. The most recent definition of the genus Pontonia Latreille, 1829, has been provided by Holthuis (1951). Pseudopontonia differs from that genus particularly in the marked reductions of some elements of the mouthparts, i.e. the basial endite if the maxilla is short and simple, not bilobed; the flagellum of the exopod of the first maxilliped is reduced, lacking distal plumose setae; the exopod of the second maxilliped is short, phylliform, lacking distal plumose setae, with sparsely plumose lateral setae; exopod of the third maxilliped is markedly reduced, with sparsely plumose distomedial setae. Other features that differ between the two genera are the presence of a blunt posterolateral angle of the sixth abdominal segment in Pseudopontonia, with also the lack of a posterolateral spine or tooth on the exopod of the uropod. The presence of six pairs of posterior telson spines in Pseudopontonia contrasts strongly with the usual pontoniine quota of three pairs found in most species of Pontonia. The correspondence of these spines in both the South Australian and New South Wales specimens indicates that these are a normal and not pathological feature in these shrimps. The occurrence of large ova and abbreviated larval development in Pseudopontonia is at present unique in the Pontoniinae (Bruce, 1972), and does not occur in Pontonia.

Remarks. The genus Pseudopontonia is monospecific. Pseudopontonia minuta is a rare shrimp, at present known only from Australia. The pair of type specimens were described by Baker (1907) from an unidentified locality in South Australia, and a single ovigerous female, from Meroo Point, New South Wales, has since been recorded (Bruce, 1972). Although undoubtedly a commensal species, the host animal is unknown. An association with nereid worms has been suggested (Bruce, 1983).

The type specimens of P. minuta are held in the collections of the South Australian Museum, catalogue number SAM C625; the Meroo Point female is in the Australian Museum, catalogue number P. 17411.

Etymology. From pseudes, Greek, false, and Pontonia, a generic name first used for a pontoniine shrimp by Latreille (1829). Gender, feminine.

\section{Anchiopontonia gen. nov.}

Definition. Small-sized shrimps of siightly depressed body form. Rostrum well developed, acute, compressed, lacking lateral carinae, feebly dentate distally. Carapace smooth, glabrous, orbit feebly developed, inferior orbital angle vestigial, antennal spine acute, supraorbital, epigastric and hepatic spines absent, anterolateral branchiostegite not produced, rounded. Abdomen smooth, glabrous, pleura rounded, posterolateral angle of sixth segment bluntly truncate. Telson with two pairs of very large, anteriorly situated, laterally highly mobile dorsal spines; three pairs of smaller posterior spines. Antennule normal, flagella short. Antenna normal, basicerite un- 
armed, scaphocerite well developed. Eye normal, cornea globular. Epistome unarmed. Mandible normal, slender, without palp, molar process stout, incisor process dentate, short; maxillula with bilobed palp, laciniae normal, not broadened; maxilla with simple palp, basal endite feebly bilobed, coxal endite distinct, exopod with caridean lobe well developed, flagellum broad, densely setose distally, epipod small, bilobed; second maxilliped with normal exopod with flagellum broad, densely setose distally, epipod small, simple, without podobranch; third maxilliped with endopod slender, ischiomerus feebly separated from basis, exopod well developed, setose distally, coxa with oval lateral plate, without arthrobranch; paragnaths short, broad, basal portion feebly carinate. Fourth thoracic sternite without median process. First pereiopod slender, chela with fingers simple. Second pereiopods with chelae well developed, subequal, similar, fingers without molar process or fossa. Ambulatory pereiopods normal, dactyls swollen, not ventrally carinate, with acute ventral accessory tooth, unguis with lamellar distolateral expansions. Uropod with protopod unarmed, exopod with small mobile spinule only distolaterally. Associated with bivalve molluscs.

Type species. Pontonia hurii Holthuis, 1981.

Systematic position. Closely related to the genus Pontonia Latreille, 1827, Anchiopontonia may be readily distinguished from all species of that protean genus by the highly characteristic dactyls of the ambulatory pereiopods. The laminar lateral expansions of the unguis are without parallel in the Pontoniinae. All other species of Pontonia so far described (excluding $P$. minuta referred to above and possibly $P$. medipacifica Edmondson) have the posterolateral angle of the sixth abdominal segment at least feebly produced and subacute, and not bluntly truncate as in Anchiopontonia. The very large anteriorly situated dorsal telson spines in $A$. hurii are highly mobile in the lateral plane and are capable of abduction to lie at about $90^{\circ}$ to the sagittal plane. They have very little or no dorsal mobility. When fully abducted, with the telson slightly flexed, they abut on to the posterolateral angle of the sixth abdominal segment and are clearly correlated with its truncated shape. The truncate posterolateral angle of the sixth abdominal segment and the anterior position and high lateral mobility of the dorsal telson spines are clearly a single functional character. A. hurii may be most closely related to the other species of Pontonia that have long dorsal telson spines, although in most of these they are not so anteriorly situated. These include $P$. ascidicola Borradaile, $P$. okai Kemp, $P$. anachoreta Kemp, $P$. stylirostris Holthuis, and $P$. monnioti Bruce in the Indo-West Pacific region. These species are all associated with tunicate hosts and have elongated ambulatory dactyls with strong recurved distal accessory teeth, with a series of small teeth along the compressed ventral border of the corpus, some of which may be anteroverted. The condition in $P$. medipacifica is uncertain. The dorsal telson spines are large and anteriorly placed, but the shape of the posterolateral angle of the sixth abdominal segment is unrecorded. The mouthparts are generally as in $P$. pinnophylax, except that the lobes of the basal endite of the maxillula are much reduced. The ambulatory dactyl is distinctive, unlike any other Pontonia species, biunguiculate with a row of rounded tubercles along the ventral border of the corpus, although it may be noted that these of $P$. ascidicola and $P$. monnioti are also blunt (Holthuis, 1952, fig. 81) when compared with those of $P$. okai and $P$. anachoreta, as illustrated by Kemp (1922, fig. 95). P. stylirostris also has blunt ventral teeth on the corpus. However, all these species have the main accessory tooth situated distally, not centrally, on the corpus. $P$. ascidicola also shows reduction of the lobes of the basal endite of the maxilla, which further suggests that it is quite closely related to 


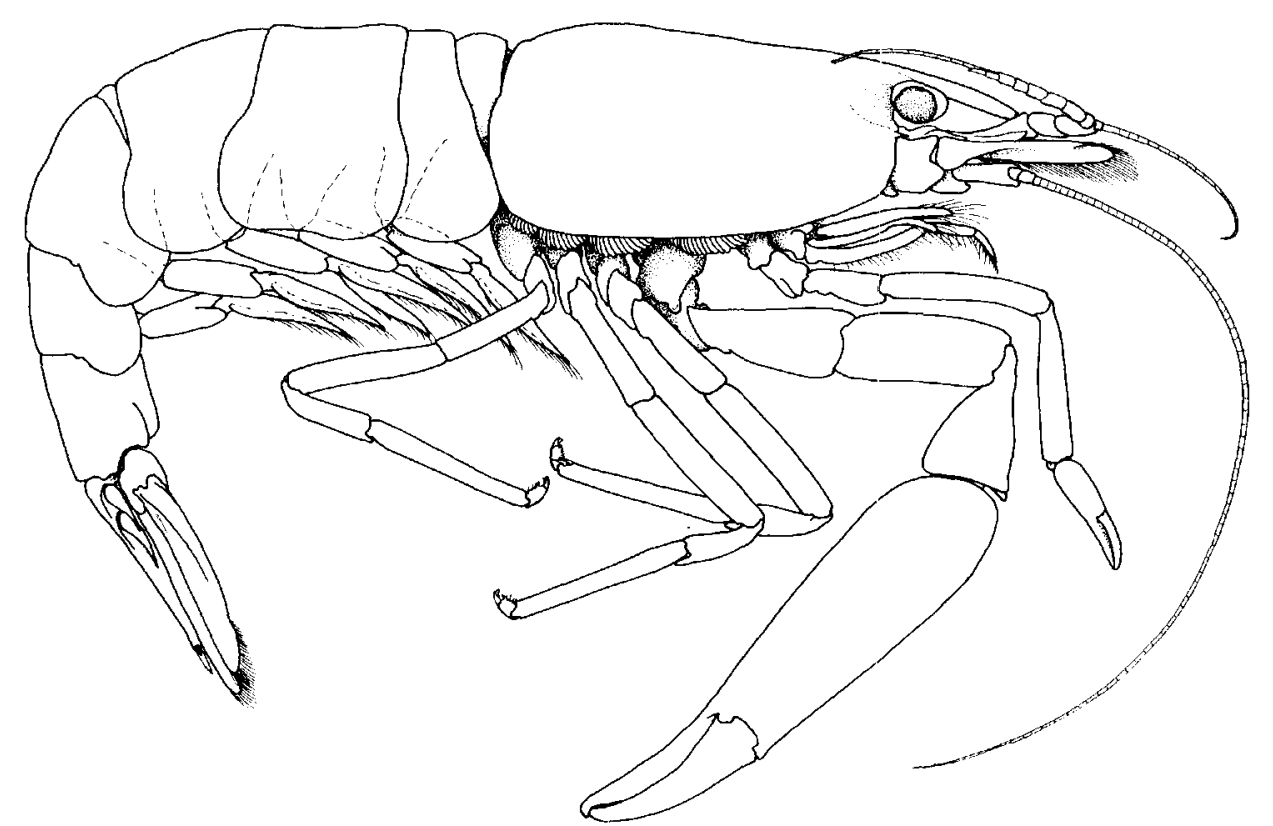

FIG. 1. Anchiopontonia hurii (Holthuis), comb. nov., male, Ryukyu Islands. Scale divisions in millimetres.

$P$. medipacifica and that both species are, for the present, correctly included in the genus Pontonia.

Remarks. The genus Anchiopontonia is monospecific. The dactyls of the commensal species of pontoniine shrimp present many features that are of diagnostic value at the level of both species and genus. In many taxa the genus is instantly recognizable by the form of the ambulatory dactyl. The dactyls of the various species of Pontonia s. str. show a wide range of variation, suggesting a polyphyletic origin (Bruce, 1991), but none shows any resemblance to those of $A$. hurii. Although $A$. hurii is known to associate with spondylid bivalve molluses (Holthuis, 1981), none of the other pontoniine shrimps associated with these hosts, Pontonia ardeae Bruce (1981), Paranchistus spondylis Suzuki (1971), Paranchistus nobilii Holthuis (1952), shows any parallel morphological adaptation. The corpus of the ambulatory dactyls in $A$. hurii presents a rather swollen appearance, without a sharply carinate ventral margin, whereas in many Pontonia species these are compressed with a sharp ventral margin.

Etymology. From anchi, Greek, near, and Pontonia, a generic name first used for a pontoniine shrimp by Latreille, 1829. Gender, feminine

Anchiopontonia hurii (Holthuis) comb. nov.

(Figs 1-4)

Pontonia hurii Holthuis, 1953: 57; Wiens, 1962: 275; Bruce, 1975: 162 (nomina nuda).

Pontonia hurii Holthuis, 1982: 796-800, fig. 4. 


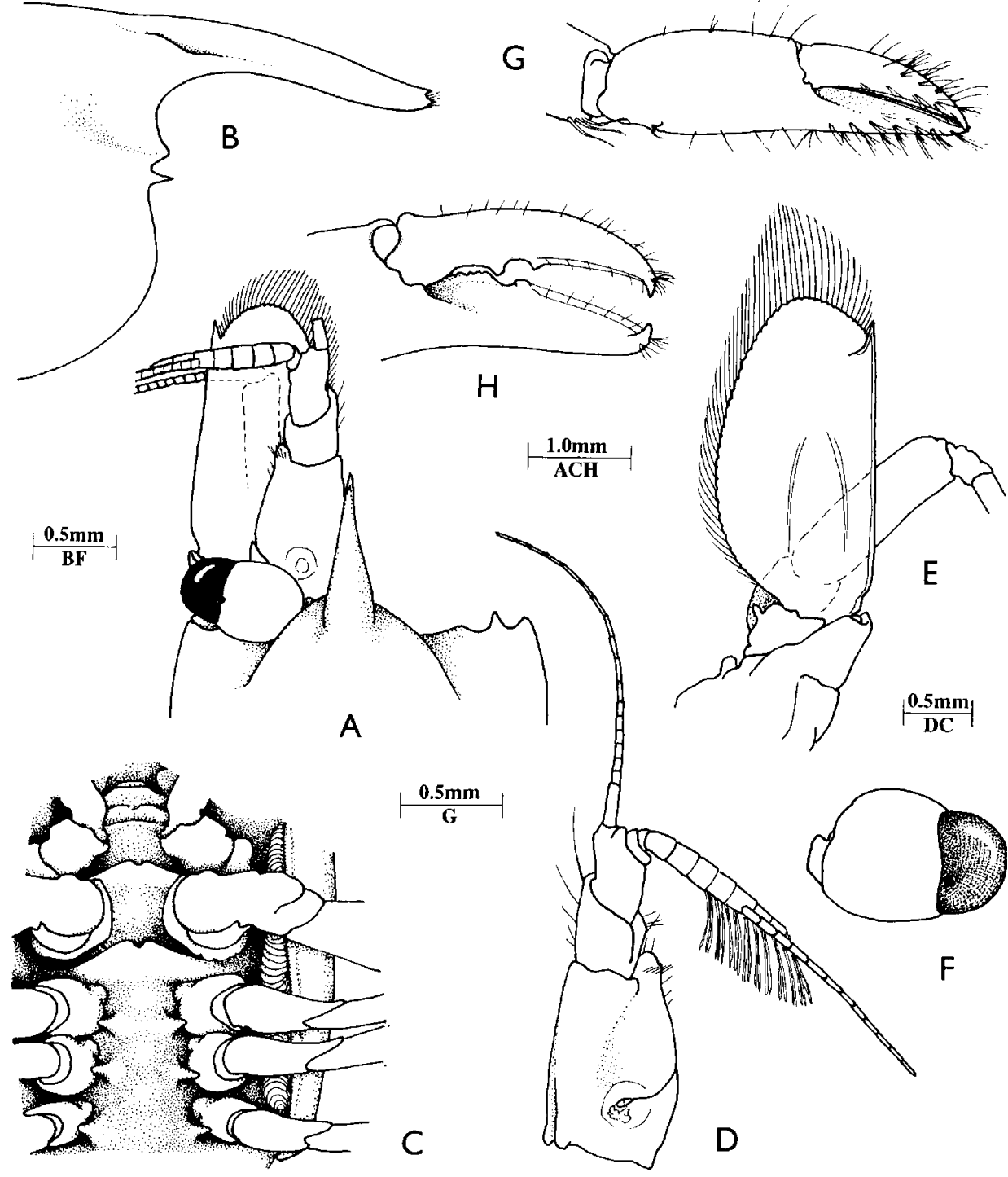

FIG. 2. Anchiopontonia hurii (Holthuis), comb. nov., male. A: Anterior carapace, rostrum, left eye and antennal peduncles, dorsal; $\mathbf{B}$ : anterior carapace and rostrum, lateral; $\mathbf{C}$ : thoracic sternites, ventral; D: antennule; E: antenna; F: eye, dorsal; G: first pereiopod chela; $\mathbf{H}$ : left second pereiopod, fingers of chela.

Material examined. $1 \delta^{\star}$, stn. RFB 1206, Okinawa, Ryukyu Islands, Japan, $26^{\circ} 30 \cdot 4 \mathrm{~N}$. $127^{\circ} 52.6 \mathrm{E}, 51.8 \mathrm{~m}$, coll. R. F. Bolland, 30 June 1984, USNM 251878.

Remarks. A general description of $A$. hurii has been provided by Holthuis (1981), with which the present specimen closely agrees. The rostrum bears a small acute dorsal tooth distally, with also a minute preterminal ventral tooth, the interspaces bear some short median plumose setae. In addition to the small acute marginal antennal spine, a small blunt inferior orbital angle is also present. The orbit is feebly developed. The posteroventral angle of the sixth abdominal segment is feebly produced and blunt, 
the posterolateral angle short and truncated. The dorsal spines of the telson are particularly large, both pairs placed on the anterior fourth and arise from deep fossae, the anterior pair about $0 \cdot 18$ of the telson length, the posterior pair about $0 \cdot 2$. Both pairs are highly mobile in the horizontal plane only and extend to right angles to the median plane. When the telson is slightly flexed, the anterior pair abut against the truncate posterolateral angle of the sixth abdominal segment. The spines are slightly swollen proximally and their medial surfaces appear flattened. The posterior telson spines have the intermediate spines bluntly swollen, subcylindrical, about 4.0 times longer than the basal diameter, very blunt distally, 0.16 of telson length; the submedian spines setulose, slightly longer than the lateral spine length. The anterolateral angle of the proximal segment of the antennular peduncle is bluntly produced with a minute preterminal distolateral tooth.

The mouthparts of Pontonia pinnophylax (Otto), the type species of the genus Pontonia Latreilic, have recently been redescribed (Bruce, 1991). The mouthparts of A. hurii are generally similar. The mandibles show no significant differences. The maxillula in $A$. hurii has narrow upper and lower laciniae, the swollen lower lacinia of $P$. pinnophylax presenting quite a different appearance. The palp has the lower lobe with a small upturned spinule noted by Holthuis, in contrast to a short recurved spinule in $P$. pinnophylax. The maxilla has the basal endites more feebly developed and the scaphognathite distinctly broader, probably correlated with the more depressed body form in $A$. hurii. The first maxilliped has the basial and coxal endites short and broad, distinctly separated, flattened, and medially fringed with sparse short simple setae. In $P$. pinnophylax these endites are fused, markedly elongated and narrow, deeply concave, with a dense medial fringe of long, finely plumose setae. The caridean lobe in $A$. hurii is short and broad and the epipod is distinctly bilobed. In $P$. pinnophylax the caridean lobe is elongate and narrow, and the epipod is suboval. The second maxillipeds are similar, but in $A$. hurii the epipod is elongate, in $P$. pinnophylax subcircular. The third maxilliped in $A$. hurii has the ischiomerus comparatively narrow and robust, distinctly separated from the basis. In $P$. pinnophylax, the ischiomerus is broad and compressed, convex, and indistinctly separated from the basis. The flagella of all exopods are broad, strap-like, with numerous plumose setae. The paragnaths have small simple alae and the corpus is short and broad, with a pair of poorly indicated submedian ridges posteriorly in $A$. hurii, of quite different appearance to $P$. pinnophylax, in which the alae appear trilobate, with the corpus narrow, elongate, with a deep ventromedian fissure posteriorly.

The thoracic sternites in $A$. hurii are moderately broad: the first bears a short low transverse ridge; the second has a more conspicuous transverse ridge with a small median notch; the third has a low simple transverse ridge; fourth and fifth sternites are wider, slightly convex anteriorly, with a broad triangular ridge posteriorly, with a small median notch, the fifth much larger than the fourth; sixth to eighth sternites narrower, but broadening posteriorly, unarmed. In $P$. pinnophylax the median notch in the transverse ridges of the fourth and fifth sternites is much larger, so that these sternites appear to have paired lateral plates.

The chelae of the first pereiopod has the fingers with simple entire laterally situated cutting edges, with feebly hooked tips. The second pereiopods are as previously described. The ambulatory pereiopods are provided with characteristic dactyls without parallel in the Caridea. The unguis is distinctly demarcated from the corpus, about $2 \cdot 0$ times longer than its basal width, curved, with distal laminar expansions, similar on medial and lateral sides, extending to tip to form a sharply convex distal margin, 


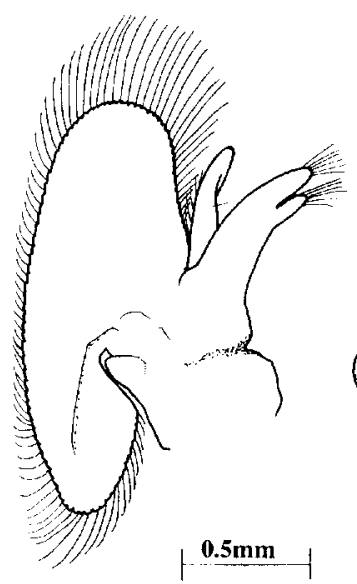

C
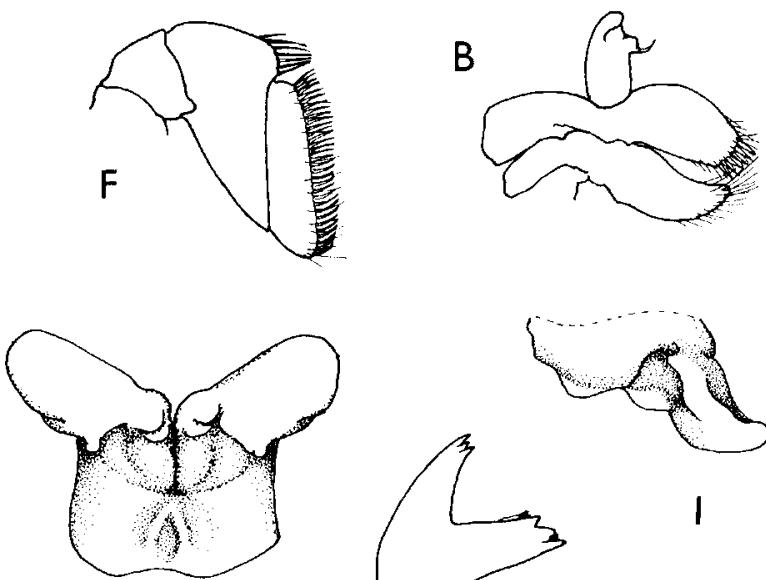

$\mathrm{H}$

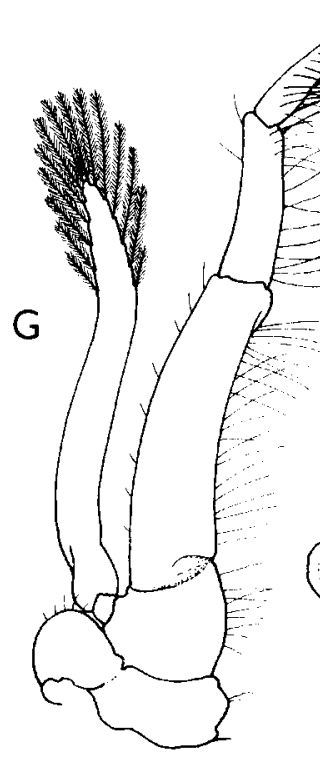

FIG. 3. Anchiopontonia hsrii (Holthuis), comb. nov., male. A: Mandible; B: maxillula; C: maxilla; D: first maxilliped; $\mathbf{E}$ : second maxilliped; F: third maxilliped; G: paragnaths, ventral; $\mathbf{H}$ : same, right lateral.

described as chisel-like by Holthuis, but possibly more like a gouge, and similarly developed on fourth and fifth pereiopods. The corpus is compressed about 1.6 times longer than basal width, tapering feebly distally, dorsal margin convex, ventral margin sublinear, with single slender, acute anteroverted, finely serrulate tooth at about $0.5-0.6$ of the ventral border length; the corpus also bears several ventrolateral setae. The propod bears large medial and lateral simple distoventral spines, with a similar preterminal ventral spine on the third propod only.

The first pleopod of the present male specimen has the endopod about 3.0 times longer than its proximal width, feebly tapering and blunt distally, medial margin 


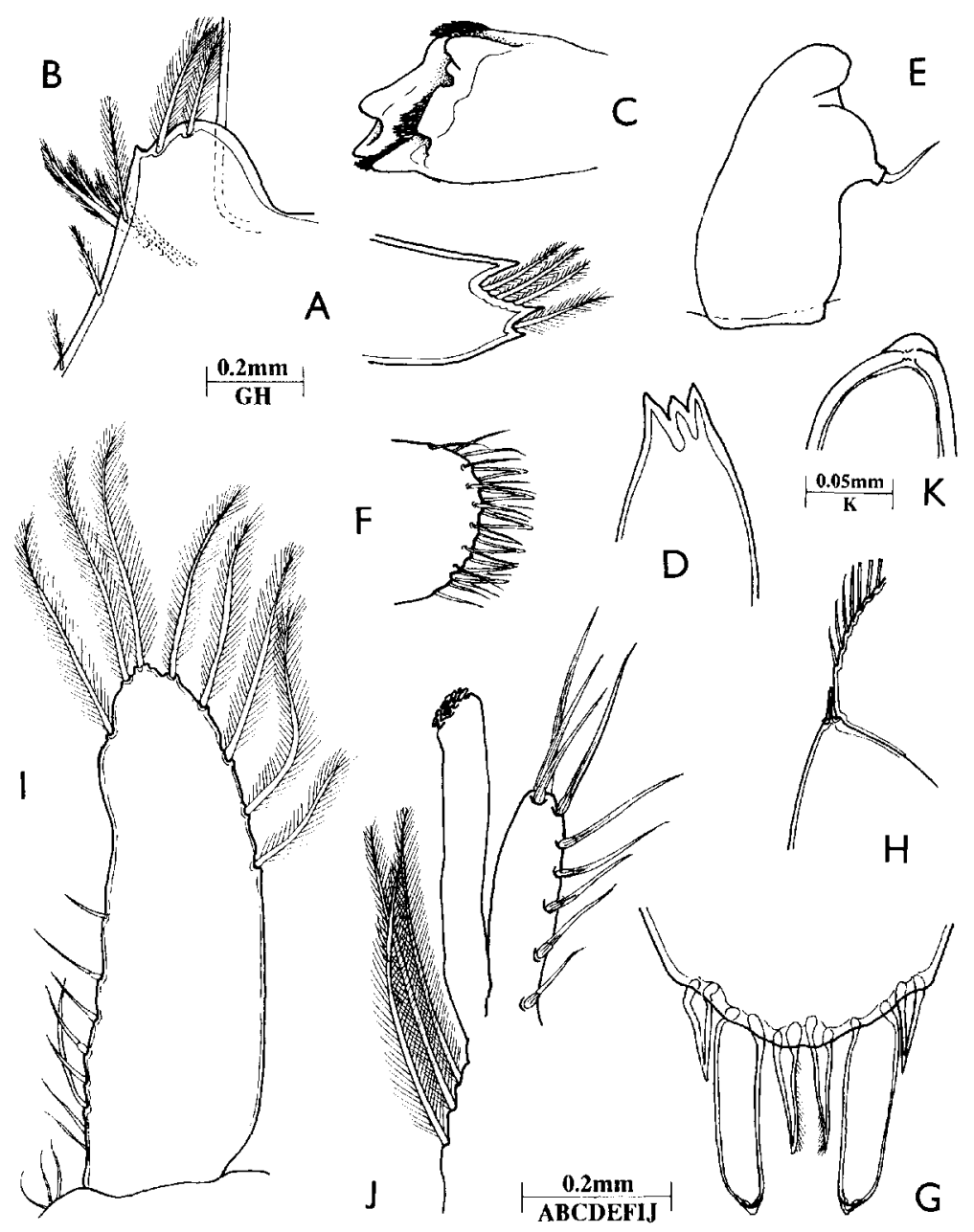

FIG. 4. Anchiopontonia hurii (Holthuis), comb. nov., male. A: Tip of rostrum; B: proximal segment of antennular peduncle, distolateral angle; $\mathbf{C}$ : molar process of mandible; $\mathbf{D}$ : incisor process of mandible; $\mathbf{E}$ : palp of maxillula; $\mathbf{F}$ : distal end of lower lacinia of maxillula; $\mathbf{G}$ : posterior telson spines; $\mathbf{H}$ : posterolateral angle of exopod of uropod; I: endopod of first pleopod; $\mathbf{J}$ : appendix interna and appendix masculina of endopod of second pleopod; K: tip of intermediate posterior telson spine.

sublinear, proximal half with 2 simple setae proximally, 6 short slender spines distally; distolateral margin with 8 plumose setae. The second pleopod has the appendix masculina with the corpus subcylindrical, very slightly swollen centrally, 3-3 times longer than wide, 0.66 of the appendix interna length, with 3 long simple terminal spines, 6 similar spines of proximally decreasing length, along ventrolateral border. The uropod has the posterolateral angle of the protopodite bluntly rounded; the exopod has a distinct diaeresis with the lateral margin bearing a small simple spinule and lacking a posterolateral tooth.

The present record presents a considerable extension of both the geographic and 
bathymetric range of this species, the Tuamotu specimens were from 9 to $10 \mathrm{~m}$, and confirm the association of this species with spondylid bivalves.

Measurements $(\mathrm{mm})$. Postorbital carapace length, 5.0; carapace and rostrum, 7.0; total body length, 18.7 ; second pereiopod chela, left; $7 \cdot 0$; same, right, 7.0.

Host. Spondylus varius Sowerby [Mollusca: Spondylidae].

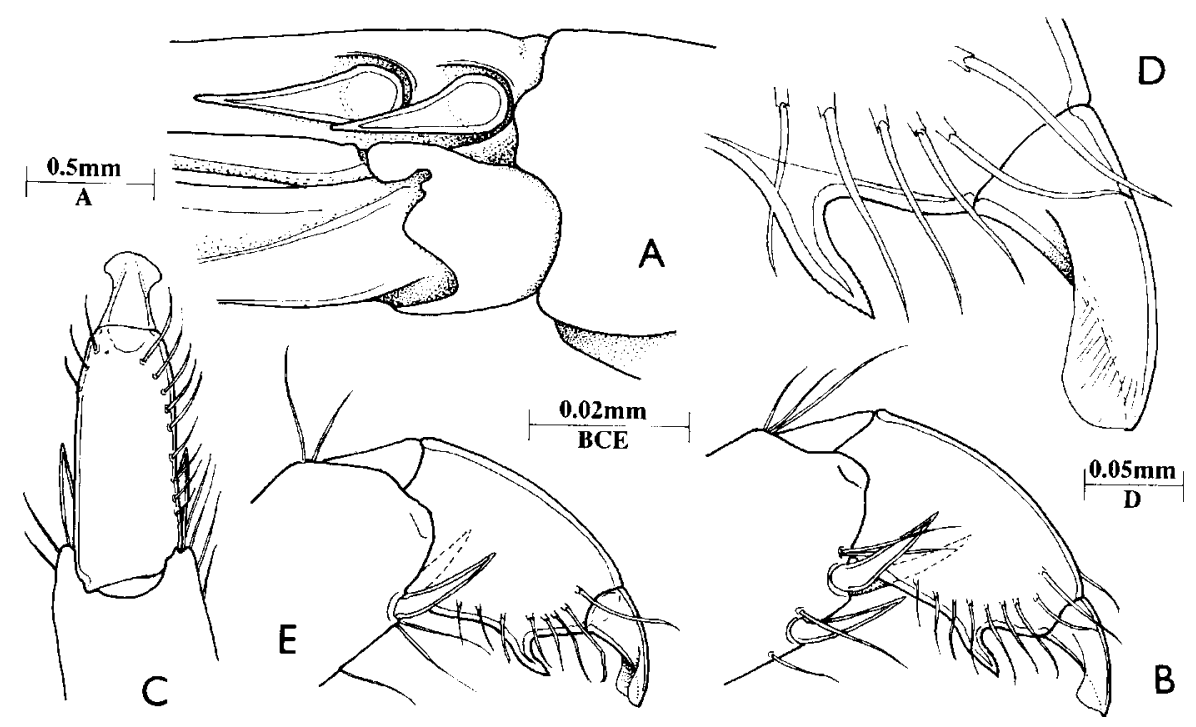

FIG. 5. Anchiopontonia hurii (Holthuis), comb. nov., male. A: Posterior sixth abdominal segment, anterior telson and right uropod, lateral aspect; $\mathbf{B}$ : third pereiopod, distal propod and dactyl, lateral; $\mathbf{C}$ : same, dorsal; D: same, dactyl, distal corpus and unguis; $\mathbf{E}$ : fifth pereiopod, distal propod and dactyl.

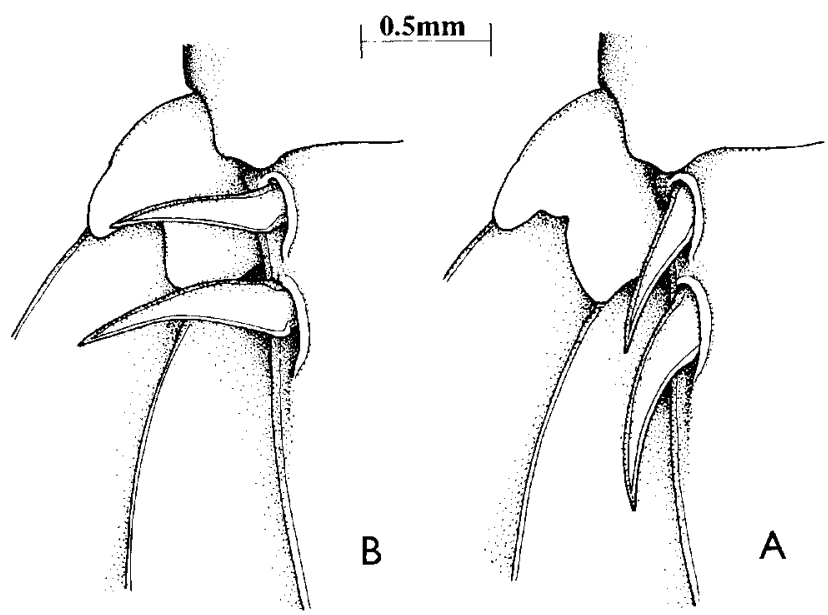

FIG. 6. Anchiopontonia hurii (Holthuis), comb. nov., male. A: Left anterolateral region of caudal fan, dorsal telson spines adducted; B: same, dorsal telson spines abducted. 
Distribution. Type locality: Amo Atoll, Marshall Islands. Also known from Tepatahiti Island, Raroia Atoll, Tuamotu Islands. All specimens found in association with Spondylus sp.

\section{Acknowledgement}

I am most grateful to Dr Raphael Lemaitre, of the Smithsonian Oceanographic Sorting Centre, for making the specimen of $A$. hurii available for study.

\section{References}

BAKER, W. H., 1907, Notes on South Australian Decapod Crustacea, V. Transactions of the Royal Society of South Australia, 31, 173-191, pls 13-15.

Bruce, A. J., 1972, Notes on some Indo-Pacific Pontoniinae, XXIII. A redescription of Pontonia minuta Baker, 1907, and the occurrence of abbreviated larval development in the Pontiniinae (Decapoda Natantia, Palaemonidae), Crustaceana, 23 (1), 65-75, figs 1-5.

Bruce, A. J., 1975, Notes on some Indo-Pacific Pontoniinae, XXVI. Neoanchistus cardiodytes gen. nov., sp. nov., a new mollusc-associated shrimp from Madagascar (Decapoda: Palaemonidae), Crustaceana, 29 (2), 149-165, figs 1-7.

Bruce, A. J., 1981, Notes on some Indo-Pacific Pontoniinae, XXXVI. Pontonia ardeae sp. nov., a new bivalve associate from the Capricorn Islands, Crustaceana, 40 (2), 113-126, figs 1-8.

BruCE, A. J., 1983, The pontoniine shrimp fauna of Australia, Australian Museum Memoirs, 18, $195-218$.

BRUCE, A. J., 1991, Notopontonia platycheles, new genus, new species (Decapoda: Pontoniinae) from South Australia, with remarks on Pontonia pinnophylax (Otto), the type species of the genus Pontonia Latreille, Journal of Crustacean Biology, 11 (4): 607-628, figs 1-14.

Holthuis, L. B., 1951, A general Revision of the Palaemonidae (Crustacea Decapoda Natantia) of the Americas. I. The subfamilies Euryrhynchinae and Pontoniinae, Allan Hancock Foundation Publications, Occasional Paper, 11, 1-322, pls 1-63.

Holthuis, L. B., 1952, The Decapoda of the Siboga Expedition, XI. The Palaemonidae collection by the Siboga and Snellius Expeditions with remarks on other species. II. Subfamily Pontoniinae, Siboga Expedition Monograph, 39a' ${ }^{10}$ : 1-252, figs 1-110, table 1.

Holthuss, L. B., 1953, Enumerations of the decapod and stomatopod Crustacea from Pacific coral islands, Atoll Research Bulletin, 24, 1-66, maps 1, 2.

Holinuis, L. B., 1981, Description of three new species of shrimps (Crustacea: Decapoda: Caridea) from Pacific Islands, Proceedings of the Biological Society of Washington, 94 (3), 787-800, figs $1-4$.

KEMP, S., 1922, Notes on Crustacea Decapoda in the Indian Museum, XV. Pontoniinae, Records of the Indian Museum, 24, 113-288, figs 1-105, pls 3-9.

Latreille, P. A., 1829, Crustacés, Arachnides et partie des Insectes, in G. Cuvier, Le regne animale distribué d'aprés son organisation, pour servir de base à l'anatomie comparée, 2nd edition, 4, 1-584.

SuzukI, H., 1971, On some commensal shrimps found in the western region of Sagami Bay, Researches on Crustacea, 4, 1-25, figs 1-12, pls 1-3.

WiENS, H. J., 1962, Atoll Environment and Ecology (New Haven and London: Yale University Press), 532 pp., figs 1-93, pl. 88. 